\title{
New treatment options for lupus - a focus on belimumab
}

This article was published in the following Dove Press journal:

Therapeutics and Clinical Risk Management

25 January 2012

Number of times this article has been viewed

\section{Laurent Chiche ${ }^{1,2}$ \\ Noémie Jourde ${ }^{3}$ \\ Guillemette Thomas' \\ Nathalie Bardin ${ }^{2}$ \\ Charleric Bornet ${ }^{4}$ \\ Albert Darque ${ }^{4}$ \\ Julien Mancini ${ }^{5}$}

'Department of Internal Medicine, Centre de Compétence Maladies

Auto-immunes Systémiques PACA Ouest, ${ }^{2}$ Laboratory of Immunology,

${ }^{3}$ Department of Nephrology,

${ }^{4}$ Department of Pharmacy, Hôpital de la Conception, Marseille; ${ }^{5}$ Department of Public Health, Hôpital de la Timone, Marseille, France
Correspondence: Laurent Chiche Department of Internal Medicine, Centre de Compétence PACA Ouest des Maladies Auto-immunes Systémiques, Hôpital de la Conception, I47 Bd Baille, I3005, Marseille, France Tel +33491383409

Fax +33491383768

Email laurent.chiche@ap-hm.fr
Abstract: Belimumab is the first biologic approved for patients with systemic lupus erythematosus (SLE). Belimumab is the first of a new class of drug targeting B cell-stimulating factors or their receptors to reach the market. Its target, BLyS, also known as BAFF (B cellactivating factor from the tumor necrosis factor family), is a type II transmembrane protein that exists in both membrane-bound and soluble forms. Additionally to a robust rational from murine experiments conducted in lupus prone mice, BLyS circulating levels are increased in SLE patients. After the negative results of a Phase II trial, two Phase III trials met their primary endpoints. Some SLE patients are still refractory to the standard options of care or necessitate prolonged high-dose corticotherapy and/or long-term immunosuppressive regimens. However, some experts still feel that the effect of this biologic might not be clinically relevant and blame the use of the new systemic lupus response index as well as the discrepancies between both trials and the noninclusion of the severe form of the disease as nephritis. In this review, we aim to discuss the characteristics of belimumab, critically evaluate the different steps of its development, and consider its future place in the arsenal against SLE, taking into account the patients' perspectives.

Keywords: systemic lupus erythematosus, belimumab, treatment, monoclonal antibodies, adverse effects, BLyS

\section{Introduction}

Although biologics have largely revolutionized the management of patients with rheumatoid arthritis (RA) during the past decade, ${ }^{1}$ belimumab, the first biologic for patients with systemic lupus erythematosus (SLE), developed by Human Genome Sciences Inc, (HGS, Rockville, MD) in collaboration with GlaxoSmithKline (Research Triangle Park, NC), was only approved in 2011 by the US Food and Drug Administration (FDA) and the European Medicines Agency (EMA). ${ }^{2,3}$

For many reasons, this approval was considered an important milestone for SLE, but also, more broadly, in the field of systemic autoimmune diseases. Firstly, this is the first approval for $>50$ years by the FDA of a drug for this indication, which explains the hopes raised among patients and physicians who had become accustomed to using mostly off-label drugs (Table 1). Secondly, belimumab is the first biologic to be directly derived from genomics to reach the market. It is the result of the "proof of principle" that has translated the data generated by the Human Genome Project into clinical practice. ${ }^{4}$ Thirdly, belimumab is also the first drug to have a successful B cell-targeting strategy. It may rebalance the failure to obtain significant results in recent prospective trials using other B-cell depletive approaches, ${ }^{5,6}$ and could pave 
Table I Drugs used to treat lupus with or without label

\begin{tabular}{llll}
\hline Drugs & FDA & EMA & AFSSAPS \\
\hline Prednisone & $\checkmark$ & NA & $\checkmark$ \\
Prednisolone & $\checkmark$ & NA & $\checkmark$ \\
Methylprednisolone & $\checkmark$ & NA & $\checkmark$ \\
Aspirine & $\checkmark$ & NA & - \\
NSAIDs & - & NA & - \\
Chloroquine & - & NA & $\checkmark$ \\
Hydroxychloroquine & $\checkmark$ & NA & $\checkmark$ \\
Thalidomide & - & - & $\S$ \\
Azathioprine & - & NA & $\checkmark$ \\
Cyclophosphamide & - & NA & $\checkmark$ \\
Methotrexate & - & NA & - \\
Mycophenomate mofetil & - & - & - \\
Cyclosporine & - & NA & - \\
Rituximab & - & - & $\S$ \\
Belimumab & $\checkmark^{*}$ & $\checkmark * *$ & NA \\
\hline
\end{tabular}

Notes: $\checkmark$, approval; - , no approval; NA, no evaluation available; $\S$, special authorizations: thalidomide for severe cutaneous lupus, rituximab for severe SLE refractory to immunosuppressants and/or plasmapheresis ("Protocole Thérapeutique Temporaire"). *Seropositive patients, with SLE refactory to standard regimen; **seropositive patients, with SLE refractory to standard regimen and positive antiDNA antibodies and low complement levels.

Abbreviations: FDA, Food and Drug Administration; EMA, European Medicines Agency; AFFSAPS, Agence Française de Sécurité Sanitaire des Produits de Santé.

the way towards developing new targeted agents for this disease (Table 2).

However, many clinicians in the field do not share this enthusiasm, ${ }^{7,8}$ and their pessimistic comments on this recently labeled drug may antagonize other physicians and patients. Indeed, from a scientific point of view, the most surprising aspect is probably that some physicians persist in supporting rituximab for SLE, although it has failed to meet its primary endpoints in two prospective Phase III trials. ${ }^{5,6}$ This is in contrast to belimumab, which has provided positive results in two prospective Phase III trials that have included about 1700 SLE patients ${ }^{9,10}$ and have followed FDA recommendations. ${ }^{11}$

In this review, we discuss the characteristics of belimumab, critically evaluate the different steps in its development, and assess its future place in the arsenal against SLE.

\section{Management issues for lupus}

SLE is a chronic autoimmune disease involving multiple organs with a large diversity of possible clinical manifestations, including, among others, arthritis, pleuritis, pericarditis, stroke, seizure, nephritis, anemia, thrombocytopenia, photosensitivity, and rash. ${ }^{12}$ The disease primarily affects women of child-bearing age, and has a prevalence of up to 1.5 million in the USA alone. ${ }^{12}$ SLE evolution is characterized by inflammatory flare-ups that can ultimately cause permanent damage to multiple organ systems, which explains why it has one of the highest mortality rates among autoimmune diseases. ${ }^{12,13}$

Current treatment options to relieve symptoms and control the progression of SLE include antimalarial drugs (mainly hydroxychloroquine), steroidal and nonsteroidal anti-inflammatory agents, nonspecific immunosuppressive drugs, including methotrexate, azathioprine, cyclophosphamide, cyclosporine, mycophenolate mofetil (MMF), and biologics. However, only a few of these drugs have been approved (Table 1), hydroxychloroquine being the last drug

Table 2 Drugs targeting BLyS pathway under development for SLE

\begin{tabular}{|c|c|c|c|c|}
\hline Company & $\begin{array}{l}\text { Product/route } \\
\text { of administration }\end{array}$ & Target & $\begin{array}{l}\text { Status and ongoing or planned trials } \\
\text { (www.clinicaltrials.gov) }\end{array}$ & Evaluation \\
\hline $\begin{array}{l}\text { Human Genome } \\
\text { Sciences Inc/ } \\
\text { GlaxoSmithKline }\end{array}$ & $\begin{array}{l}\text { Benlysta belimumab } \\
\text { LymphoStat-B } \\
\text { intravenous }\end{array}$ & $\begin{array}{l}\text { Human mAb targeting } \\
\text { soluble BLyS (BAFF) }\end{array}$ & $\begin{array}{l}\text { Approved by FDA and EMA } \\
\text { NCT00724867 NCT007I } 2933 \\
\text { NCT00583362 Phase III (long-term safety) } \\
\text { NCT0I } 345253 \text { PhIII (Asia) } \\
\text { NCT00732940 Phase II (Subcutaneous) }\end{array}$ & SRI \\
\hline Eli Lilly & $\begin{array}{l}\text { LY2I } 27399 \\
\text { Subcutaneous }\end{array}$ & $\begin{array}{l}\text { Human mAb targeting } \\
\text { soluble and membrane- } \\
\text { bound BLyS (BAFF) }\end{array}$ & NCT0I I9609I NCT0I 205438 Phase III & SRI \\
\hline Merck KGaA/ & Atacicept (TACl-Ig) & BLyS and APRIL & NCT00573I 57 Phase II/III* & Renal response \\
\hline Bristol-Myers Squibb & Subcutaneous & $\begin{array}{l}\text { (Soluble fusion protein } \\
\text { containing the extracellular } \\
\text { portion of TACl linked to Fc) }\end{array}$ & $\begin{array}{l}\text { NCT00624338 Phase II/III } \\
\text { NCT0I } 44023 \text { I Phase II (dose response*) }\end{array}$ & $\begin{array}{l}\text { BILAG } \\
\text { SRI-50 }\end{array}$ \\
\hline Anthera & A-623 AMG 623 & Peptide fusion protein that & NCT0I395745 Phase II & SRI \\
\hline $\begin{array}{l}\text { Pharmaceuticals Inc/ } \\
\text { Amgen }\end{array}$ & $\begin{array}{l}\text { Blisibimod } \\
\text { Subcutaneous }\end{array}$ & $\begin{array}{l}\text { antagonizes soluble and } \\
\text { membrane-bound BLyS (BAFF) }\end{array}$ & $\begin{array}{l}\text { NCTOI I6268I Phase II } \\
\text { NCTOI } 305746 \text { Phase II (safety) }\end{array}$ & SLE response** \\
\hline
\end{tabular}

Notes: *Dose of 5 to $115 \mathrm{mg} /$ weekly because $150 \mathrm{mg}$ dose judged unfavorable in renal Phase II/III trials; **SLE response is defined as the percentage of subjects with SLE response compared with baseline at the time of assessment (SRI included in secondary endpoints).

Abbreviations: BILAG, British Isles Lupus Assessment Group; SLE, systemic lupus erythematosus; SRI, SLE Response Index. 
to be labeled by the FDA for SLE in the 1950s. In many countries, a "graduated" therapeutic escalation has been recommended. ${ }^{14}$ Standard options of care (SOC) for mild to moderate SLE consist of nonsteroidal anti-inflammatory drugs (NSAIDs), antimalarials, and corticosteroids, while life-threatening flare-ups, such as those affecting the kidneys or central nervous system (CNS), are treated with high-dose corticosteroids, and immunosuppressive agents such as cyclophosphamide and azathioprine, or MMF. Importantly, recent immunological and clinical research strongly supports the broad use of antimalarials for all SLE patients (including patients receiving immunosuppressants) to help prevent complications. ${ }^{13,15,16}$

In spite of this arsenal, some patients are still refractory to SOC or need prolonged high-dose corticotherapy and/or a long-term immunosuppressive regimen to maintain remission. In many cases, the drugs themselves cause irreversible damage, sometimes leading to death. Among other serious side effects, corticosteroids cause weight gain, hypertension, increased susceptibility to infection, osteoporosis, while immunosuppressants increase the risk of infections (including opportunist pathogens), malignancy, and infertility. Actually, avoiding this "collateral" damage is the strongest rationale for the development of biologics. Unfortunately for SLE patients, so far, available biologics have been either not recommended, such as tumor necrosis factor (TNF) blockers that can induce $\mathrm{SLE}^{17}$, or have not gained approval in prospective evaluations, such as rituximab. ${ }^{5,6}$ In this context, belimumab has just been labeled, but its place in the management of SLE is already a matter of debate, as evidenced, for example, by the discrepancies between the labeling given by the FDA and EMA (Table 1).

\section{Pharmacology, mode of action, and pharmacokinetics of belimumab}

To most immunologists, the physiopathology of SLE is so complex that the identification of a single factor/molecule that can mirror TNF- $\alpha$ for RA seemed until recently nearly impossible. ${ }^{18}$ Nevertheless, the rationale for developing B-lymphocyte (BLy) inhibitors has been robust and has included successive in vitro, murine, and human investigations.

SLE is a systemic autoimmune disease characterized by autoantibody production against self-antigens (Ags). B-cell stimulatory factors that can promote the loss of B-cell tolerance and drive autoantibody production are exciting new candidates. In 1997, HGS discovered and rapidly identified the function of the B-lymphocyte stimulator (BLyS) protein. ${ }^{19}$ BLyS, also known as BAFF (B-cell-activating factor from the TNF family), is a type II transmembrane protein that exists in both membrane-bound and soluble forms. ${ }^{19}$ BLyS is expressed at the surface of a wide variety of immune cell types (monocytes, activated neutrophils, T cells, and dendritic cells), and its expression/secretion can be increased by various inflammatory cytokines. ${ }^{20,21}$

When cleaved from the membrane, BLyS becomes a soluble trimer that is a ligand for three receptors expressed primarily on B lymphocytes (Figure 1): BLyS receptor 3 (BR3 or BAFF-R), transmembrane activator-1, calcium modulator and cyclophilin ligand-interactor (TACI), and B-B-lymphocyte stimulator cell maturation antigen (BCMA). BLyS is the sole ligand for BR3, whereas TACI and BCMA can each bind with BLyS or another TNF family ligand known as a proliferation-inducing ligand (APRIL). These ligand-receptor interactions vary in affinity and BLyS binds more strongly to BR3 than to TACI or BCMA. In theory, APRIL can mediate effects similar to those of BLyS, but as the three BLyS family receptors vary in their expression patterns and levels across different B-cell subsets, its biologic action may be primarily on memory and plasma cells (Figure 1). In vitro, BLyS exhibits a strong costimulatory function on B-cell activation that leads to B-cell and plasma cell proliferation, differentiation, and survival, and to immunoglobulin $\mathrm{G}(\mathrm{IgG})$ class switching. ${ }^{19}$

Interestingly, results from murine models have indicated that increased expression of BLyS may lead to systemic autoimmune disease in mouse models and constitutes one of the first clues for a potential role for BLyS in human autoimmune disease. First, BLyS-transgenic mice developed severe B-cell hyperplasia and autoimmune lupus-like disease, characterized by the presence of autoantibodies against nuclear Ags and immune complex deposits in the kidneys. ${ }^{22,23}$ Secondly, in two murine models of human SLE (MRL/Mp-lpr/lpr and NZB/W F1 mice), there were increased serum levels of BLyS that correlated with autoimmune kidney damage, and treatment with soluble BLyS receptors significantly improved survival of these lupus mice. ${ }^{24}$

In SLE patients, two cross-sectional studies have shown that serum levels of BLyS were significantly increased in a third of patients, ${ }^{25,26}$ and were associated with IgG levels and antidouble-stranded DNA (anti-dsDNA) titers. Of note, this increase was not specific to SLE, as high circulating BLyS levels were also observed in patients with RA, Sjögren, and antineutrophil cytoplasmic antibodies (ANCA)-associated vasculitis. ${ }^{27-29}$ Although patients with positive antinuclear antibodies (ANA), but no other American College of Rheumatology (ACR) criteria for lupus, had marginally 


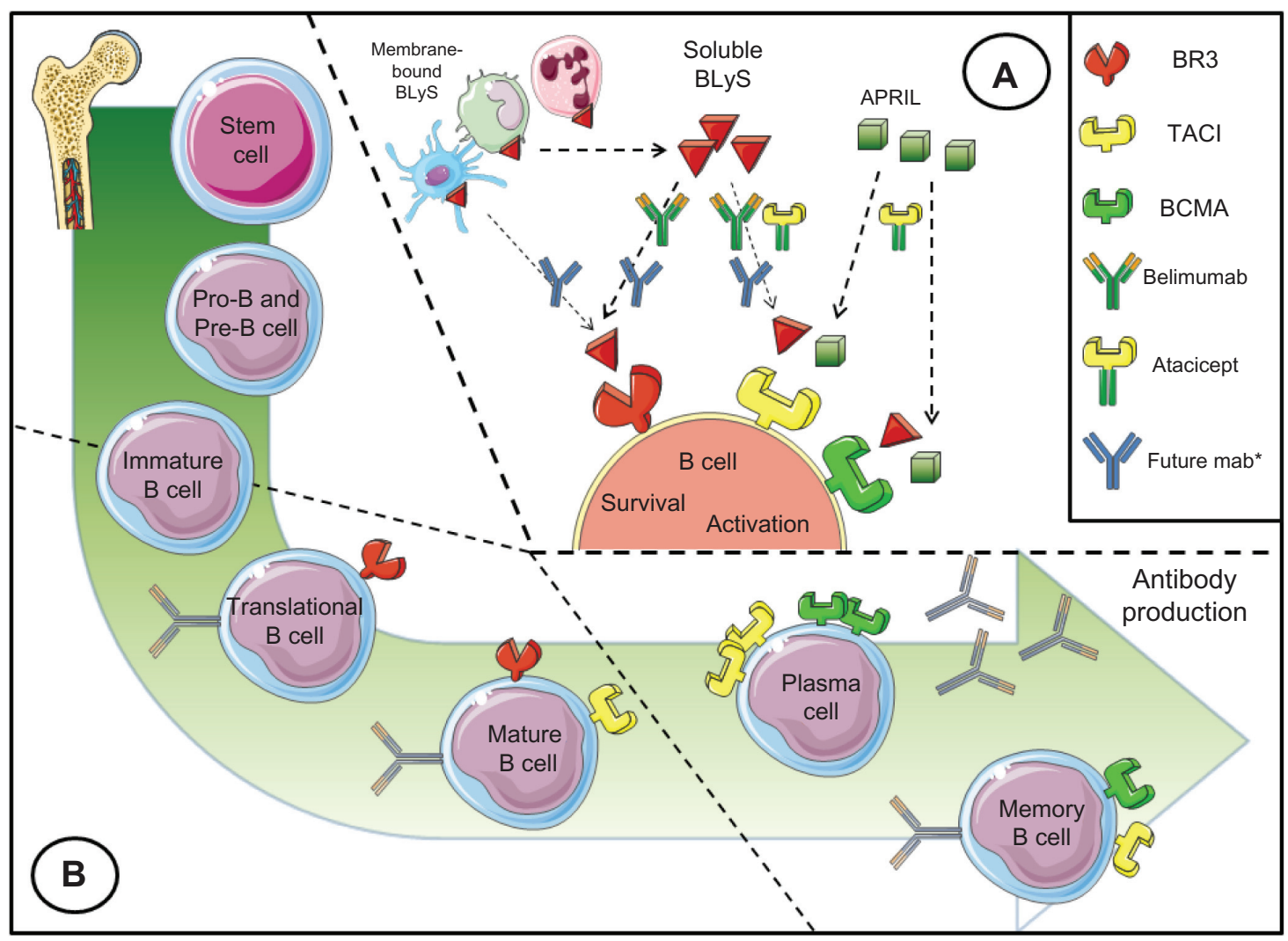

Figure I BLyS, its receptors and "anti-BLyS" biologics. (A) BLyS exists in both membrane-bound form (at the surface of a wide variety of cell types as monocytes, activated neutrophils, T cells, and dendritic cells) and, after cleavage, soluble form, that is a ligand for three receptors on B lymphocytes: BLyS receptor 3 (BR3), transmembrane activator-I and calcium modulator and cyclophilin ligand-interactor (TACl), and B cell maturation antigen (BCMA). BLyS is the sole ligand for BR3, whereas TACl and BCMA each can bind either BLyS or another ligand known as a proliferation-inducing ligand (APRIL). Belimumab blocks only soluble BLyS, whereas atacicept also blocks APRIL and other drugs (see Table $2^{*}$ ) also aim at membrane-bound BLyS. (B) The three BLyS family receptors vary in their expression patterns and levels across different B cell subsets, explaining why belimumab has little biologic action on memory and plasma cells.

elevated BLyS levels, those with positive ANA and several criteria for lupus had higher levels. However, in these studies, BLyS levels were not correlated with SLE activity when evaluated with the SLE Disease Activity Index (SLEDAI). ${ }^{25,26}$

To explain this lack of correlation, let us keep in mind that some pieces of the BLyS puzzle remain unanswered in humans (Figure 1). First, a 60-mer form of soluble BLyS (BLyS-60) has been observed in mice ${ }^{30}$ and in vitro evidence suggests that BLyS-60 binds to TACI with 100-fold greater affinity than the canonical trimeric BLyS. ${ }^{31}$ However, the existence of a soluble BLyS-60 remains to be determined in humans. Secondly, BLyS-APRIL heterotrimers have also been characterized, but their function in vivo is unclear. ${ }^{32}$ Third, BLyS can be expressed as a membrane-bound protein by immune and also nonhematopoietic cells (osteoclasts and synovial fibroblasts). ${ }^{33}$ Finally, some have recently emphasized the contribution of BCMA in the production of autoantibodies, ${ }^{34}$ while others have reported an inverse correlation between APRIL and both BLyS levels and disease activity in SLE patients, suggesting a protective role for APRIL. ${ }^{35}$ In addition, a trial that tested atacicept (Figure 1) in another autoimmune condition, multiple sclerosis, was recently stopped because of an unexpected pro-inflammatory effect: ${ }^{36}$ this illustrates the limitations in our comprehension of this complex pathway.

The interpretation of BLyS levels is difficult in some specific settings. On the one hand, some have suggested that glomerulonephritis may increase BLyS excretion in the urine, thereby resulting in paradoxically lower plasma BLyS levels in patients with very active disease.$^{37}$ On the other hand, the influence of certain drugs on BlyS/B-cell biology are also probably underestimated: as an example, rituximab-induced B-cell depletion is followed by an increase in BLyS level, which then returns to near-baseline levels when B cells are repopulated in ANCA vasculitis, RA, and SLE patients. ${ }^{38,39}$ Finally, in a longitudinal study, using multivariate analysis with complex adjustments, Petri et al found that the level of BLyS at one patient's visit was positively correlated with the increase in SELENA-SLEDAI (SS) score at the 
following visit, ${ }^{37}$ thus providing the missing link between in vitro/murine and human data.

Belimumab (Benlysta ${ }^{\circledR}$; HGS) is a fully human $\operatorname{IgG} 1 \lambda$ recombinant monoclonal antibody directed against BLyS. Specific binding of belimumab with soluble BLyS prevents its interaction with its three receptors and indirectly decreases B-cell survival and production of autoantibodies. ${ }^{40}$ Although TACI and BCMA also bind to APRIL, BLyS is BR3's only ligand and the interaction of BLyS and BR3 is necessary for survival of naïve B cells and mature primary B cells. This enables belimumab to have a greater effect on early B cells, such as naïve $B$ cells, and a lesser effect on memory and plasma B cells (Figure 1).

Belimumab is the first of a new class of drugs to target B-cell stimulating factors or their receptors (Table 2). Importantly, in contrast to other drugs under development (Table 2), belimumab does not neutralize membrane-bound BLyS (Figure 1). Belimumab is administered intravenously from single-use vials containing 120 or $400 \mathrm{mg}$ of lyophilized powder that is reconstituted to obtain $10 \mathrm{mg} / \mathrm{kg}$ of belimumab administered over 1 hour. The first three doses are administere every 2 weeks and then treatment is repeated every 4 weeks. A Phase I dose-ranging randomized controlled trial on 70 SLE patients demonstrated in vivo safety and provided pharmacokinetic data. ${ }^{40}$ The half-life of belimumab is 19-20 days, its volume of distribution is small (69-112 mL/kg), and clearance is slow (7 mL/day/kg). No significant pharmacokinetic change is seen with concomitant use of belimumab and NSAIDs, antimalarials, corticosteroids, methotrexate, azathioprine, or MMF; however, there are no available data concerning previous or ongoing administration of other biologics such as rituximab.

\section{Efficacy studies, including any comparative studies}

The following logical step in the development of belimumab was to conduct a Phase II double-blind randomized controlled trial on 449 SLE patients assigned to either belimumab $(1,4$, or $10 \mathrm{mg} / \mathrm{kg}$ ) or a placebo, administered intravenously on days 0,14 , and 28 , and then every 28 days for 52 weeks. ${ }^{41}$ All subjects also received the SOC, with a stable regimen of steroids, antimalarials, or immunosuppressants for 60 days prior to the first belimumab dose. Unfortunately, there were no significant differences between the treated and placebo groups regarding efficacy endpoints (percentage of change in the SS score at 24 weeks and the time to first SLE flare-up), and no dose response was observed in this trial. However, some secondary results were considered interesting. First, the time until a first flare-up was longer with belimumab (154 days in the combined belimumab group compared to 104 days with the placebo, $P=0.036$ ). This suggests that the drug could have a postponed effect, which is not visible at 24 weeks: indeed, a significant decrease in the mean physician's global assessment (PGA) score at 52 weeks was noted (31\% with belimumab compared to $14 \%$ with the placebo, $P=0.0019$ ).

Secondly, post-hoc analysis of the subgroup of patients with serologically active disease (ANA $>1: 80$ and/or antidsDNA > $30 \mathrm{IU} / \mathrm{mL}$ ) yielded significantly better responses at 52 weeks in belimumab- versus placebo-treated patients by SS score and PGA. This subset of patients exhibited higher disease activity (especially with regards to biologic markers) at baseline compared to ANA-negative patients. Finally, the large and poorly controlled use of corticosteroids was identified as a potential cause for the negative results in Phase II studies. In addition, in two later negative Phase II/III studies that tested rituximab in SLE patients, corticosteroids were blamed for masking the effect of the biologic therapy. ${ }^{5,6}$ All these points have led to major modifications in the design of Phase III trials for belimumab.

The most important measures were the restriction of inclusion to seropositive patients, and the introduction of a novel tool to assess changes in disease activity, which was used as the primary endpoint: the Systemic Lupus Erythematosus Responder Index (SRI). In this compound index, SS scores were utilized to define global improvement, British Isles Lupus Assessment Group (BILAG) domain scores to ensure no significant worsening in previously unaffected systems, and PGA to ensure that improvement in disease activity was not achieved to the detriment of the patient's overall condition. From reanalysis of Phase II data, the SRI was defined as a $\geq 4$ point reduction in SS score compared to baseline, plus no worsening (increase $<0.3$ points from baseline) in PGA score, plus absence of any new BILAG organ domain score of A or two new BILAG scores of $B$ at week 52 compared to baseline. BILAG scores A and B, respectively, indicated a severe and moderate flare-up in any of the eight organ domains of the index..$^{42}$

Two multicenter Phase III trials, BLISS-52 and BLISS-76, have been simultaneously conducted. In both trials, seropositive patients were randomized to one of three treatment groups: $10 \mathrm{mg} / \mathrm{kg}$ belimumab, $1 \mathrm{mg} / \mathrm{kg}$ belimumab, or a placebo. SOC therapy was given to all enrolled patients in addition to respective treatment. Intravenous belimumab was administered on days 0,14 , and 28 , then every 28 days thereafter for the duration of the study. In the BLISS-52 trial, ${ }^{9}$ which enrolled 
865 seropositive patients, SRI rates were observed to be significantly higher in the belimumab-1 and 10-mg/kg group than with the placebo group at the end of week 52 (Table 3), whereas no significant difference was found between belimumab and the placebo with respect to adverse effects. In the BLISS76 trial, ${ }^{10} 819$ seropositive patients were observed for 76 weeks. The patients' response rates, to be measured by SRI at weeks 52 and 76, were the primary and major secondary endpoints, respectively. No significant SRI improvement was seen with belimumab at $1 \mathrm{mg} / \mathrm{kg}$ compared to the placebo. However, the improvement was significantly higher in the $10-\mathrm{mg} / \mathrm{kg}$ belimumab group than the placebo by week 52 , but could not be sustained later and the difference by week 76 was not statistically significant (Table 3 ). The results of these two studies, compatible with the June 2010 FDA guidelines, ${ }^{11}$ led to approval of belimumab in March $2011,{ }^{2}$ but deserve additional comments to explain the skepticism of some reports. ${ }^{7,8}$

First, some have criticized the use of a novel (and automatically poorly validated) composite endpoint to evaluate disease activity that was designed by HGS, namely SRI. The goal of devising a composite endpoint was to ensure that belimumab did not improve some manifestations at the expense of others. Whereas SS captures only the presence or absence of symptoms at a given point in time, BILAG captures improvement or worsening within eight organ systems. However, although the BILAG was the preferred index for measuring disease reduction, ${ }^{11}$ the FDA had previously approved the choice of SRI. Nevertheless, it is important to note that choosing particular combinations of these parameters is not negligible. The different sensitivity of SS and BILAG might possibly provide totally different results with the same combination of parameters when used in a different way. This has been recently reported in an ongoing trial that compared SRI and BILAG-based Combined Lupus Assessment. ${ }^{43}$

The FDA and other experts have been concerned that only part of the scale was being used due to the exclusion of severe renal and CNS disease, and that a 4-point difference in scores might not be clinically meaningful using a reduced scale, especially as an ACR committee had concluded that a decrease of 7 points in SS was clinically meaningful. ${ }^{44}$

Table 3 Efficacy results of belimumab in BLISS-52 and BLISS-76 Phase III trials

\begin{tabular}{|c|c|c|c|c|c|c|}
\hline & \multicolumn{3}{|c|}{ BLISS-52 (study C I 057) } & \multicolumn{3}{|c|}{ BLISS-76 (study CI 056) } \\
\hline & $\begin{array}{l}\text { Placebo } \\
(n=287)\end{array}$ & $\begin{array}{l}\text { Benlysta } \\
\text { I mg/kg } \\
(\mathrm{n}=288)\end{array}$ & $\begin{array}{l}\text { Benlysta } \\
10 \mathrm{mg} / \mathrm{kg} \\
(\mathrm{n}=290)\end{array}$ & $\begin{array}{l}\text { Placebo } \\
(n=275)\end{array}$ & $\begin{array}{l}\text { Benlysta } \\
\text { I mg/kg } \\
(n=27 \text { I })\end{array}$ & $\begin{array}{l}\text { Benlysta } \\
10 \mathrm{mg} / \mathrm{kg} \\
(\mathrm{n}=273)\end{array}$ \\
\hline \multicolumn{7}{|l|}{ Primary endpoint } \\
\hline SRI & $125(44 \%)$ & | 48 (5|\%) & $167(58 \%)$ & $93(34 \%)$ & $110(4 \mid \%)$ & $118(43 \%)$ \\
\hline Difference vs placebo & & $8 \%$ & $14 \%$ & & $7 \%$ & $9 \%$ \\
\hline OR $[95 \% \mathrm{Cl}]$ vs placebo & & $1.55[1.10,2.19]$ & $1.83[1.3,2.59]$ & & $1.34[0.94,1.91]$ & $1.52[1.07,2.15]$ \\
\hline$P$-value & & 0.0129 & 0.0006 & & 0.1041 & 0.0207 \\
\hline \multicolumn{7}{|l|}{ Subcomponents } \\
\hline 4 -point reduction in & 132 (46\%) & $153(53 \%)$ & 169 (58\%) & $98(36 \%)$ & II 6 (43\%) & $128(47 \%)$ \\
\hline OR $[95 \% \mathrm{Cl}]$ vs placebo & & $1.51[1.07,2.14]$ & I.7I $[1.2 \mathrm{I}, 2.4 \mathrm{I}]$ & & $1.36[0.96,1.93]$ & $1.63[1.15,2.32]$ \\
\hline$P$-value & & 0.0189 & 0.0024 & & 0.0869 & 0.0062 \\
\hline No worsening in PGA & $199(69 \%)$ & 227 (79\%) & $231(80 \%)$ & $173(63 \%)$ & 197 (73\%) & $189(69 \%)$ \\
\hline OR $[95 \% \mathrm{Cl}]$ vs placebo & & $1.68[1.15,2.47]$ & $1.74[1.18,2.55]$ & & $1.60[1.11,2.30]$ & $1.32[0.92,1.90]$ \\
\hline$P$-value & & 0.0078 & 0.0048 & & 0.012 & 0.1258 \\
\hline No new BILAG & $210(73 \%)$ & $226(79 \%)$ & $236(81 \%)$ & 179 (65\%) & 203 (75\%) & 189 (69\%) \\
\hline OR $[95 \% \mathrm{Cl}]$ vs placebo & & $1.38[0.93,2.04]$ & $1.62[1.09,2.42]$ & & $1.63[1.12,2.37]$ & $1.20[0.84,1.73]$ \\
\hline$P$-value & & 0.1064 & 0.0181 & & 0.0108 & 0.3193 \\
\hline \multicolumn{7}{|c|}{ Secondary endpoints on efficacy } \\
\hline \multicolumn{7}{|l|}{ SLE Flares over $52 \mathrm{~W}$} \\
\hline Median Time to first & 84 & 126 & 119 & 82 & 85 & 84 \\
\hline \multicolumn{7}{|l|}{ SELENA-SLEDAI Flare (days) } \\
\hline OR $[95 \% \mathrm{Cl}]$ vs placebo* & & $0.75[0.62-0.90]$ & $0.76[0.63-0.91]$ & & $0.89[0.74-1.08]$ & $0.93[0.78-1.13]$ \\
\hline$P$-value & & 0.0026 & 0.0036 & & 0.2324 & 0.4796 \\
\hline SRI W76 & - & - & - & $89(32 \%)$ & $106(39 \%)$ & 105 (39\%) \\
\hline Difference vs placebo & & - & - & & $7 \%$ & $6 \%$ \\
\hline OR $[95 \% \mathrm{Cl}]$ vs placebo & & - & - & & $1.3[0.9-1.9]$ & $1.3[0.9-1.9]$ \\
\hline$P$-value & & - & - & & 0.10 & 0.13 \\
\hline
\end{tabular}

Note: *Median time to first flare was not available in the original paper, ${ }^{10}$ and corresponding hazard ratios were taken from the FDA official document. ${ }^{2}$

Abbreviations: BILAG, British Isles Lupus Assessment Group; CI, confidence interval; OR, Odds Ratio; PGA, physician's global assessment; SRI, SLE Response Index; W, week. 
But post hoc sensitivity analyses showed that patients receiving belimumab had a significantly greater rate of SRI response when higher SS thresholds of 5, 6, and 7 were used. ${ }^{45}$

In addition, although the designs of the two Phase III trials were identical (except that patients in the BLISS-52 trial were treated for 48 weeks, and those in BLISS-76 continued treatment until 72 weeks), discrepancies exist between their results, which may be explained in part by some of the difference in the selected patients (Table 4), which leads to questions about the generalizability of these results. As an example, the less favorable results in the BLISS-76 trial could suggest decreased efficacy of belimumab in patients with late established SLE, as the mean disease duration of enrolled patients was longer in the BLISS-76 trial, and BLISS 52 included almost no black patients, who have been shown to be unresponsive to belimumab in these studies.

Also, the management of other therapies was of concern. No new immunosuppressants were permitted

Table 4 Difference in patients' characteristics between the belimumab Phase III trials

\begin{tabular}{|c|c|c|}
\hline Phase 3 trials & $\begin{array}{l}\text { BLISS-52 } \\
\text { (CI057) }\end{array}$ & $\begin{array}{l}\text { BLISS-76 } \\
(C \mid 056)\end{array}$ \\
\hline $\begin{array}{l}\text { Disease duration } \\
\text { (year), mean }\end{array}$ & 5.3 & 7.5 \\
\hline BILAG IA/2B, \% & 58 & 64 \\
\hline SELENA-SLEDAI & 9.8 & 9.7 \\
\hline Renal, \% & 20 & II \\
\hline Musculoskeletal, \% & 59 & 73 \\
\hline Cutaneous, \% & 82 & 82 \\
\hline Immunology, \% & 85 & 74 \\
\hline ANA positive, $\%$ & 95 & 92 \\
\hline Anti-DNA positive, $\%$ & 75 & 64 \\
\hline Low C4, \% & 59 & 53 \\
\hline $\begin{array}{l}\text { SLICC/ACR damage } \\
\text { index }\end{array}$ & 0.57 & 0.99 \\
\hline Antimalarials, $\%$ & 67 & 63 \\
\hline Corticosteroids, \% & 96 & 76 \\
\hline Prednisone $>7.5$ mg/day, \% & 69 & 46 \\
\hline Immunosuppressant, \% & 42 & 56 \\
\hline Geographic regions, \% & $\begin{array}{l}\text { Latin America } 50 \\
\text { Asia } 38 \\
\text { Eastern Europe II } \\
\text { Australia } 2\end{array}$ & $\begin{array}{l}\text { USA/Canada } 53 \\
\text { Western Europe/ } \\
\text { Israel } 25 \\
\text { Eastern Europe II } \\
\text { Latin America II }\end{array}$ \\
\hline Ethnicity, \% & & \\
\hline Caucasian & 27 & 70 \\
\hline Asian & 38 & 3 \\
\hline Black/African American & 4 & 14 \\
\hline $\begin{array}{l}\text { Alaskan Native/ } \\
\text { American Indian }\end{array}$ & 32 & 13 \\
\hline
\end{tabular}

Abbreviations: ANA, antinuclear antibodies; BILAG, British Isles Lupus Assessmen Group; C4, complement fraction C4; SLICC, Systemic Lupus International Collaborative Clinics/American College of Rheumatology Damage Index. after randomization, and no increases in dose of immunosuppressants or antimalarials was allowed after week 16. Increases of steroids were limited after week 24. Thus, because these trials evaluated efficacy at 52 weeks (instead of the 24-week evaluation period in the Phase II trial), this seemed to evaluate the capacity of belimumab to maintain the response obtained after initial changes in SOC. Also, patients who required changes to background medications that were not permitted by the protocol were scored as treatment failures, which happened more often in the placebo group, and might have exaggerated the effect of belimumab. However, this point was also addressed by further sensitivity analyses. ${ }^{2}$

Finally, the clinical relevance of this new therapy has been questioned. The trials enrolled a total of 1684 patients who were positive for autoantibodies and had SS scores $\geq 6$. The most commonly involved organ systems were musculoskeletal (60\%), mucocutaneous (59\%), hematologic (16\%), renal $(11 \%)$, general $(11 \%)$, and vasculitis $(9 \%)$ : there were no data from patients who had involvement of organ systems associated with mortality (CNS or proliferative nephritis). Even if mucocutaneous and musculoskeletal symptoms are debilitating and reduce quality of life (Qol), they are not generally lethal. This questions the relevance of the effect of belimumab, which seemed overall to be mild: this was either because there was little effect in the whole population or only a significant effect in a subset of patients. The latter hypothesis seems probable. First, the effect did not seem to concern specific subsets, as black patients given belimumab did even worse than those given a placebo in the Phase III trials. Black patients, who account for about $25 \%$ of lupus patients in the USA, tend to have more severe disease than the general lupus population. Of note, the BLISS-52 trial included no patients from the USA and had only $4 \%$ of patients with an African heritage, whereas the BLISS-76 trail had 14\% black patients, though still far from the $25 \%$ expected in the USA. Thus, the negative results in the BLISS76 trial at week 76 seem to be attributable to a lack of power due to exclusions, which implies that the huge sample size was probably one of the key factors to reach significance. In addition, required post-hoc analyses have been conducted and led EMA to restrict the label approved for belimumab to patients who are biologically active (positive anti-DNA and low complement levels), which is in contrast to the FDA recommendation. ${ }^{2,3}$

The mild and unsustained effect of belimumab, as well as the inability to clearly define which patients may benefit from belimumab, enables us to focus on the safety issues of 
this new drug and to evaluate its benefit/risk ratio, especially as this drug is intended for patients with no life-threatening form of SLE.

\section{Safety and tolerability}

As with any other newly approved molecule, the long-term safety of the drug needs to be monitored since the results of any trial cannot fully predict a drug's safety profile in real-life practice (Table 2). Apart from the limited follow up of the three prospective trials, we also have data from open follow-up periods of $>5$ years. ${ }^{46,47}$ Besides infusion reactions, such as urticaria, and hematologic reactions, such as neutropenia and thrombocytopenia, which have been reported in some patients, few serious adverse events have been reported during the clinical trials. However, serious infections and suicides, due to severe depression, have been reported more frequently with belimumab than with placebo $(0.8 \%$ vs $0.4 \%)$. Six malignancies occurred (one in a placebo patient, three on $1 \mathrm{mg} / \mathrm{kg}$, and two on $10 \mathrm{mg} / \mathrm{kg}$ ). More deaths were reported with belimumab at 1 and $10 \mathrm{mg} / \mathrm{kg}$ than with a placebo $(0.7 \%$ and $0.9 \%$ vs $0.4 \%)$. There were four deaths related to infection (one in the placebo group, three in the belimumab groups), and infection may have contributed to two more deaths in the belimumab arms.

To know whether belimumab's marginal efficacy is strong enough to justify individually the potential risks suggested by the small increases in a few serious adverse effects found in these trials, FDA calculated the death rate per 100 patient-years in the belimumab groups to be almost double that in the placebo group ( 0.79 vs 0.43 ; $95 \%$ confidence intervals [CI]: 0.49-10.08). According to statistical experts, 11 patients needed to be treated to achieve one SRI response, based on the BLISS-76 trial, and seven needed to be treated based on the BLISS-52 trial, whereas, in pooled analysis of both trials, 342 was the number needed to harm, or the number who would need to be treated before one death occurred. Thus, one death should be expected for every 30 or 50 patients who achieve an effect as the primary endpoint. However, against this pessimistic evaluation, the benefit/ ratio of initiating belimumab treatment should obviously not solely take into account the risk due to this biologic, but instead include the risk in the calculation if patients that do not receive belimumab remain dependent on other treatments, especially long-term corticosteroids and their morbidity-mortality and impact on QoL. Of course, these safety concerns require a strict long-term follow-up, especially to detect rare side effects or side effects that may be more prevalent in patients outside of trials, who often exhibit more comorbidities.

\section{Patient-focused perspectives such as QoL, patient satisfaction/acceptability, adherence, and uptake}

From a patient's perspective, the efficacy of a drug is not the only important issue. Unfortunately, results from the secondary endpoints generally did not support the primary analysis. Week 76 response rate, a secondary endpoint in BLISS-76, was not significant (Table 3). Numerically, more patients in the belimumab arms in both trials were able to reduce their steroid use by $\geq 25 \%$ to $\leq 7.5 \mathrm{mg} /$ day, a secondary endpoint. But the results were inconsistent for the other steroid-related secondary endpoint. ${ }^{2,3}$ Especially, in the BLISS-76 trial, fewer patients given $1 \mathrm{mg} / \mathrm{kg}$ belimumab needed to increase their steroid dose compared to the placebo group, but the $10-\mathrm{mg} / \mathrm{kg}$ arm needed similar steroid doses to the placebo group. ${ }^{2}$ Also, patients with a severe form of SLE, a seronegative form, or black SLE patients were not concerned by the presented results, as attested by the label attributed by the FDA and the nonbiologically active SLE patients outlined by EMA.,3

Finally, from careful examination of the data available so far, it is clear that the decision to approve belimumab was probably influenced by the lack of hope in this field, an influence that is practically impossible to avoid in severe diseases. This was recently illustrated by the withdrawal of accelerated approval for bevacizumab (Avastin; Genentech/ Roche, South San Francisco, CA) for metastatic breast cancer by the FDA: ${ }^{48}$ we fully agree that physicians and researchers have the obligation to "give hope - but not false hope". To paraphrase the recent words of Dr Sekeres, ${ }^{48}$ and of course setting aside the issue of the cost of belimumab, what kind of conversation would I have with such a patient if I were trying to convince her to take a treatment like belimumab? "Well, I can offer you a drug that will not make you live longer (belimumab was not evaluated for severe and potentially lethal forms), won't make you feel better (no clear results on quality of life or steroid sparing), and may have rare but life-threatening side effects (long-term evaluation is needed to conclude), but, considering that you are not black and that your lupus is biologically active, with a monthly infusion, it will keep your lupus from worsening for several months (negative 76 week results)." Hope? Or false hope?

The modality of administration is also an important issue with regards to patient adherence. Indeed, nonsevere patients 
are mostly managed as outpatients and because they have to come to a hospital monthly this factor probably also has a negative impact on QoL and/or adherence in some patients. However, a Phase II study on belimumab administered subcutaneously is ongoing (Table 2).

A few important issues should be evaluated before the initiation of belimumab to SLE patients refractory to SOC. First, a significant proportion of so-called refractory SLE patients are likely to have insufficient drug exposure due to either poor observance or inter-individual variability to drug metabolism, the primary source of treatment failure. Thus, adherence to treatment needs to be assessed using, among other ways, unscheduled measurement of drug blood levels, as proposed by Arnaud and colleagues, ${ }^{49}$ to avoid unnecessary therapeutic intensification. Also, physicians could ideally enroll patients with persistent nonobservance in a therapeutic education program dedicated to SLE, to maximize their general adherence to treatment. Finally, due to its good tolerance profile and efficacy, there is a consensus for giving antimalarials to all SLE patients, ${ }^{14}$ which was not the case for a third of patients in the BLISS trial (Table 4). Conversely, in cases of real intolerance or a contraindication to antimalarials, belimumab could be an interesting option instead of switching to long-term immunosuppressive treatments.

\section{Conclusion: belimumab's place in therapy}

Despite the need for huge trials and unique trial endpoints to demonstrate the drug's modest efficacy, belimumab could be useful in some carefully selected patients, and the approval of belimumab for SLE seems to be only the beginning of a long path to defining its role in real life.

In the meantime, we can already distinguish different patients/situations. First, for patients with severe flare-ups (nephritis or CNS), belimumab should not be used because there are no data available concerning these patients and because the slow onset of belimumab might not be compatible with the rapid control needed for a severe flare-up. Secondly, for patients with mild flare-ups, if they fulfill the approval terms (seropositive in the USA or seropositive with presence of anti-DNA and low complement in Europe), belimumab might be initiated in patients refractory to SOC. Nevertheless, due to the mild effect, especially on steroid sparing and some unavoidable reported serious side effects, black patients should not receive belimumab until additional data are available and only nonblack patients with real refractory disease (meaning with biologically active or high steroid dose, and good exposure/adherence to SOC, including ideally antimalarials) might be proposed for this new biotherapy. In cases of intolerance/contraindication to antimalarials, belimumab could also be a useful alternative. Initiation should be monitored across a registry, as proposed for other biologics, ${ }^{50}$ to better characterize tolerance profiles in the long term.

Finally, physicians taking care of SLE patients are well aware that there is an urgent need to individualize therapy in such a heterogeneous disease. Efforts should be made to improve identification of patients who might respond to anti-BLyS. New tools available to fully assess the immune response of SLE patients across time should be evaluated to monitor treatment and also to predict drug responders. ${ }^{51,52}$ Now that the era of biologics in SLE has come, questions about identification of appropriate lupus patients with active disease, trial endpoints, and the subgrouping of lupus patients remain, and independent efforts are needed to prevent the approval of a new biologic that relies on the use of its own "tailored" index. ${ }^{11,43}$

\section{Disclosure}

The authors report no conflicts of interest in this work.

\section{References}

1. Breedveld FC, Combe B. Understanding emerging treatment paradigms in rheumatoid arthritis. Arthritis Res Ther. 2011;13 Suppl 1:S3.

2. Human Genome Sciences, Inc. Arthritis Advisory Committee Meeting Briefing Document for the November 16, 2010 Meeting: Belimumab BENLYSTA $^{\circledR}$ (Belimumab) Treatment of Systemic Lupus Erythematosus BLA 125370. [cited October 13, 2010]. Available from: http://www.fda. gov/downloads/AdvisoryCommittees/CommitteesMeetingMaterials/ Drugs/ArthritisDrugsAdvisoryCommittee/UCM233581.pdf. Accessed January 5, 2012.

3. European Medicines Agency [homepage on the Internet]. Benlysta: belimumab. [cited August 8,2011]. Available from: http://www.ema.europa. eu/ema/index.jsp?curl=pages/medicines/human/medicines/002015/ human_med_001466.jsp\&mid=WC0b01ac058001d124. Accessed January 5, 2012.

4. Sanz I, Yasothan U, Kirkpatrick P. Belimumab. Nat Rev Drug Discov 2011;10(5):335-336.

5. Merrill JT, Neuwelt CM, Wallace DJ, et al. Efficacy and safety of rituximab in moderately-to-severely active systemic lupus erythematosus: the randomized, double-blind, phase II/III systemic lupus erythematosus evaluation of rituximab trial. Arthritis Rheum. 2010;62(1):222-233.

6. Ramos-Casals M, Díaz-Lagares C, Khamashta MA. Rituximab and lupus: good in real life, bad in controlled trials. Arthritis Rheum. 2009;61(9):1281-1282

7. Weintraub B. Belimumab efficacy is 'mild' but market potential still great: anticipating US approval of the first lupus drug since 1957. BioDrugs. 2011;25(3):203-205.

8. Mitka M. Treatment for lupus, first in 50 years, offers modest benefits, hope to patients. JAMA. 2011;305(17):1754-1755.

9. Navarra SV, Guzmán RM, Gallacher AE, et al. Efficacy and safety of belimumab in patients with active systemic lupus erythematosus: a randomised, placebo-controlled, phase 3 trial. Lancet. 2011;377(9767): $721-731$. 
10. Furie R, Petri M, Zamani O, et al. A phase III, randomized, placebocontrolled study of belimumab, a monoclonal antibody that inhibits B lymphocyte stimulator, in patients with systemic lupus erythematosus. Arthritis Rheum. 2011;63(12):3918-3930.

11. U.S. Food and Drug Administration. Guidance for Industry on Systemic Lupus Erythematosus - Developing Drugs for Treatment. [cited Jun 2010]. Available from: http://www.fda.gov/downloads/Drugs/ GuidanceComplianceRegulatoryInformation/Guidances/UCM072063. pdf. Accessed January 5, 2012.

12. Tsokos GC. Systemic lupus erythematosus. NEngl J Med. 2011;365(22): 2110-2121.

13. Pons-Estel GJ, Alarcón GS, Scofield L, Reinlib L, Cooper GS. Understanding the epidemiology and progression of systemic lupus erythematosus. Semin Arthritis Rheum. 2010;39(4):257-268.

14. Bertsias G, Ioannidis JP, Boletis J, et al. EULAR recommendations for the management of systemic lupus erythematosus. Report of a Task Force of the EULAR Standing Committee for International Clinical Studies Including Therapeutics. Ann Rheum Dis. 2008;67(2):195-205.

15. Kuznik A, Bencina M, Svajger U, Jeras M, Rozman B, Jerala R. Mechanism of endosomal TLR inhibition by antimalarial drugs and imidazoquinolines. J Immunol. 2011;186(8):4794-4804.

16. Pons-Estel GJ, Alarcón GS, González LA, et al. Possible protective effect of hydroxychloroquine on delaying the occurrence of integument damage in lupus: LXXI, data from a multiethnic cohort. Arthritis Care Res. 2010;62(3):393-400.

17. Palucka AK, Blanck JP, Bennett L, Pascual V, Banchereau J. Cross-regulation of TNF and IFN-alpha in autoimmune diseases. Proc Natl Acad Sci U S A. 2005;102(9):3372-3377.

18. Rönnblom L, Alm GV, Eloranta ML. The type I interferon system in the development of lupus. Semin Immunol. 2011;23(2):113-121.

19. Moore PA, Belvedere O, Orr A, et al. BLyS: member of the tumor necrosis factor family and B lymphocyte stimulator. Science. 1999;285(5425):260-263.

20. Ohata J, Zvaifler NJ, Nishio M, et al. Fibroblast-like synoviocytes of mesenchymal origin express functional B cell-activating factor of the TNF family in response to proinflammatory cytokines. J Immunol. 2005;174(2):864-870

21. Scapini P, Carletto A, Nardelli B, et al. Proinflammatory mediators elicit secretion of the intracellular B-lymphocyte stimulator pool (BLyS) that is stored in activated neutrophils: implications for inflammatory diseases. Blood. 2005;105(2):830-837.

22. Khare SD, Sarosi I, Xia XZ, et al. Severe B cell hyperplasia and autoimmune disease in TALL-1 transgenic mice. Proc Natl Acad Sci U S A. 2000;97(7):3370-3375.

23. Mackay F, Woodcock SA, Lawton P, et al. Mice transgenic for BAFF develop lymphocytic disorders along with autoimmune manifestations. J Exp Med. 1999;190(11):1697-1710.

24. Gross JA, Johnston J, Mudri S, et al. TACI and BCMA are receptors for a TNF homologue implicated in B-cell autoimmune disease. Nature. 2000;404(6781):995-999.

25. Zhang J, Roschke V, Baker KP, et al. Cutting edge: a role for B lymphocyte stimulator in systemic lupus erythematosus. J Immunol. 2001;166(1):6-10.

26. Stohl W, Metyas S, Tan SM, et al. B lymphocyte stimulator overexpression in patients with systemic lupus erythematosus: longitudinal observations. Arthritis Rheum. 2003;48(12):3475-3486.

27. Roschke V, Sosnovtseva S, Ward CD, et al. BLyS and APRIL form biologically active heterotrimers that are expressed in patients with systemic immune-based rheumatic diseases. J Immunol. 2002;169(8):4314-4321.

28. Candon S, Gottenberg JE, Bengoufa D, Chatenoud L, Mariette X. Quantitative assessment of antibodies to ribonucleoproteins in primary Sjögren syndrome: correlation with B-cell biomarkers and disease activity. Ann Rheum Dis. 2009;68(7):1208-1212.

29. Schneeweis C, Rafalowicz M, Feist E, et al. Increased levels of BLyS and sVCAM-1 in anti-neutrophil cytoplasmatic antibody (ANCA)-associated vasculitides (AAV). Clin Exp Rheumatol. 2010;28(1 Suppl 57):62-66.
30. Karpusas M, Cachero TG, Qian F, et al. Crystal structure of extracellular human BAFF, a TNF family member that stimulates B lymphocytes. J Mol Biol. 2002;315(5):1145-1154.

31. Bossen C, Cachero TG, Tardivel A, et al. TACI, unlike BAFF-R, is solely activated by oligomeric BAFF and APRIL to support survival of activated B cells and plasmablasts. Blood. 2008;111(3): 1004-1012.

32. Dillon SR, Harder B, Lewis KB, et al. B-lymphocyte stimulator/ a proliferation-inducing ligand heterotrimers are elevated in the sera of patients with autoimmune disease and are neutralized by atacicept and B-cell maturation antigen-immunoglobulin. Arthritis Res Ther. 2010;12(2):R48.

33. Yaccoby S, Pennisi A, Li X, et al. Atacicept (TACI-Ig) inhibits growth of TACI(high) primary myeloma cells in SCID-hu mice and in coculture with osteoclasts. Leukemia. 2008;22(2):406-413.

34. Kim J, Gross JA, Dillon SR, et al. Increased BCMA expression in lupus marks activated $\mathrm{B}$ cells, and BCMA receptor engagement enhances the response to TLR9 stimulation. Autoimmunity. 2011;44(2):69-81.

35. Morel J, Roubille C, Planelles L, et al. Serum levels of tumour necrosis factor family members a proliferation-inducing ligand (APRIL) and B lymphocyte stimulator (BLyS) are inversely correlated in systemic lupus erythematosus. Ann Rheum Dis. 2009;68(6):997-1002.

36. Hartung HP, Kieseier BC. Atacicept: targeting B cells in multiple sclerosis. Ther Adv Neurol Disord. 2010;3(4):205-216.

37. Petri M, Stohl W, Chatham W, et al. Association of plasma B lymphocyte stimulator levels and disease activity in systemic lupus erythematosus. Arthritis Rheum. 2008;58(8):2453-2459.

38. Holden NJ, Williams JM, Morgan MD, et al. ANCA-stimulated neutrophils release BLyS and promote B cell survival: a clinically relevant cellular process. Ann Rheum Dis. 2011;70(12):2229-2233.

39. Cambridge G, Stohl W, Leandro MJ, Migone TS, Hilbert DM, Edwards JC. Circulating levels of B lymphocyte stimulator in patients with rheumatoid arthritis following rituximab treatment: relationships with B cell depletion, circulating antibodies, and clinical relapse. Arthritis Rheum. 2006;54(3):723-732.

40. Furie R, Stohl W, Ginzler EM, et al. Biologic activity and safety of belimumab, a neutralizing anti-B-lymphocyte stimulator (BLyS) monoclonal antibody: a phase I trial in patients with systemic lupus erythematosus. Arthritis Res Ther. 2008;10(5):R109.

41. Wallace DJ, Stohl W, Furie RA, et al. A phase II, randomized, double-blind, placebo-controlled, dose-ranging study of belimumab in patients with active systemic lupus erythematosus. Arthritis Rheum. 2009;61(9):1168-1178.

42. Yee CS, Farewell V, Isenberg DA, et al. Revised British Isles Lupus Assessment Group 2004 index: a reliable tool for assessment of systemic lupus erythematosus activity. Arthritis Rheum. 2006;54(10):3300-3305.

43. Petri M, Pike MC, Kelley L, Kilgallen B, Gordon C. 2011. Systemic Lupus Erythematosus Responder Index Assessment of Responders in EMBLEM, a Phase Ilb Study in Patients with Moderate to Severe Systemic Lupus Erythematosus [abst]. Presented at the American College of Rheumatology Annual Meeting. November 5-9. Chicago, IL. Presentation 1378

44. American College of Rheumatology Ad Hoc Committee on Systemic Lupus Erythematosus Response Criteria. The American College of Rheumatology response criteria for systemic lupus erythematosus clinical trials: measures of overall disease activity. Arthritis Rheum. 2004;50(11):3418-3426.

45. Chiche L, Jourde N, Mancini J. Belimumab for systemic lupus erythematosus. Lancet. 2011;377(9783):2080; author reply 2080-2081.

46. Jacobi AM, Huang W, Wang T, et al. Effect of long-term belimumab treatment on B cells in systemic lupus erythematosus: extension of a phase II, double-blind, placebo-controlled, dose-ranging study. Arthritis Rheum. 2010;62(1):201-210.

47. Petri M, Furie R, Merrill JT, et al. 2011. Six-year experience with belimumab in patients with SLE [Abstract]. Presented at the European League Against Rheumatism Meeting. May 25-28. London, UK. 
48. Sekeres MA. The avastin story. $N$ Engl J Med. 2011;365(15): 1454-1455.

49. Arnaud L, Zahr N, Costedoat-Chalumeau N, Amoura Z. The importance of assessing medication exposure to the definition of refractory disease in systemic lupus erythematosus. Autoimmun Rev. 2011;10(11):674-678.

50. Terrier B, Amoura Z, Ravaud P, et al. Safety and efficacy of rituximab in systemic lupus erythematosus: results from 136 patients from the French AutoImmunity and Rituximab registry. Arthritis Rheum. 2010;62(8):2458-2466.
51. Chaussabel D, Quinn C, Shen J, et al. A modular analysis framework for blood genomics studies: application to systemic lupus erythematosus. Immunity. 2008;29(1):150-164.

52. Quartier P, Allantaz F, Cimaz R, et al. A multicentre, randomised, double-blind, placebo-controlled trial with the interleukin-1 receptor antagonist anakinra in patients with systemic-onset juvenile idiopathic arthritis (ANAJIS trial). Ann Rheum Dis. 2011;70(5):747-754.

\section{Publish your work in this journal}

Therapeutics and Clinical Risk Management is an international, peerreviewed journal of clinical therapeutics and risk management, focusing on concise rapid reporting of clinical studies in all therapeutic areas, outcomes, safety, and programs for the effective, safe, and sustained use of medicines. This journal is indexed on PubMed Central, CAS,

Submit your manuscript here: http://www.dovepress.com/therapeutics-and-clinical-risk-management-journal
EMBase, Scopus and the Elsevier Bibliographic databases. The manuscript management system is completely online and includes a very quick and fair peer-review system, which is all easy to use. Visit http://www.dovepress.com/testimonials.php to read real quotes from published authors. 